\author{
М. В. Голуб, асистент, \\ e-mail: g.nikolay@ukr.net \\ С. М. Мацепа, асистент, \\ e-mail: s_matsepa@ukr.net \\ Г. В. Канашевич, д.m.н., професор, \\ e-mail:kgv-elbeam@rambler.ru \\ О. С. Алекссєва, к.т.н., дочент, \\ e-mail: Elena_alekseeva@ukr.net \\ С. В. Хижняк, к.т.н., ст. викладач, \\ e-mail: ehizh1@yahoo.com \\ П. П. Дмитренко, асистент, \\ e-mail: mndlfm@ukr.net \\ Черкаський державний технологічний університет \\ б-р Шевченка, 460, м. Черкаси, 18006, Україна
}

\title{
МЕТАЛІЗАЦІЯ ТЕХНІЧНОГО СКЛА 3 ВИКОРИСТАННЯМ ЕЛЕКТРОННО-ПРОМЕНЕВОГО МЕТОДУ МІКРООБРОБКИ ПОВЕРХНІ
}

Представлені дані з електронно-променевої обробки для покращення адгезійної міиності металевих плівок. В основі лежсть спрямована зміна фізико-хімічних властивостей приповерхневого шару скла шляхом обробки стрічковим електронним потоком з енергією електронів E $\leq 8$ кеВ. Результати можуть бути використані в прецизійних технологіях мікрооптики та інтегральної оптики.

Ключові слова: електронний потік, електронно-променева обробка, електроннопроменева мікрообробка, приповерхневий шар скла, силікатне скло.

Актуальність. Якість металевої плівки, нанесеної у вакуумі на скло та міцність ії зчеплення визначаються способом підготовки поверхні та станом приповерхневого шару (ПШ) скла [1-4]. Пластини 3 технічного силікатного скла, поверхня яких оброблялася різними методами шліфування та полірування (механічним, хіміко-механічним, полум'яним) мають різні нанорельєф і структуру ПШ, що впливає на якість зчеплення металевої плівки 3 поверхнею [5-7, 9].

Нами запропоновано новий підхід щодо покращення адгезійних властивостей поверхні технічного скла при його металізації. В основу покладено метод обробки поверхні скла низькоенергетичним електронним потоком (енергія електронів $\mathrm{E} \leq 8$ кеВ), що приводить до спрямованої зміни фізико-хімічного стану поверхні і ПШ матеріалу.

Мета роботи. Підвищення адгезійної міцності металевої плівки до поверхні скла 3 використанням методу електроннопроменевої мікрообробки.

Обладнання і інструмент мікрооброб$\kappa и$. Вакуумна лабораторна установка, яка виготовлена на базі установки УВН 71П-3 і забезпечує нанесення тонких плівок на матеріали. В установці розміщено електронно-променеву гармату Пірса, механізм переміщення об'єктів обробки. Механізм переміщення забезпечує рух електронного потоку в камері установки зі швидкістю $\mathrm{V}_{\text {пот. }}=0 . .20 \mathrm{~cm} / \mathrm{c}$, залишковий тиск у вакуумній камері складає $10^{-4}$ Па. Електронно-променева гармата випромінює стрічковий електронний потік довжиною $l=60 \mathrm{Mм}$, шириною $b=1.5 \ldots 4,0$ мм і питомою потужністю $10^{1} \mathrm{BT} / \mathrm{cm}^{2} \leq \mathrm{P}_{\text {пит }} \leq 10^{3} \mathrm{BT} / \mathrm{cm}^{2}$.

Об'єкти обробки. Прямокутні пластини технічного скла 3 розмірами: $20 \times 20$ мм, товщиною 1 мм, які отримані механічним розділенням фотопластини (ГОСТ 10691.1-84).

Отримані результати та їх обговорення. Стрічковий електронний потік довжиною $l$ i шириною $b$ проходить по поверхні фотопластини, змінюючи при цьому температуру поверхні і ПШ.

Просторово-часова структура стрічки відповідає гаусовому розподіленню (максимальною енергією володіють електрони на вісі стрічки, мінімальною ті, які формують край стрічки).

Розподілення щільності потоку:

$$
\mathrm{F}_{\mathrm{n}}=\mathrm{F}(\mathrm{x}, \mathrm{y}, \mathrm{z}, \mathrm{t}) \text {, }
$$

де $\mathrm{x}, \mathrm{y}, \mathrm{z},-$ просторові координати, $\mathrm{t}$ - час.

Якщо нам потрібно досягти лише поверхневого термічного впливу (глибиною до 10 мкм), ми розглядаємо поверхневе джерело теплоти, яке рухається за координатами х, у. 
Якщо нам потрібно проплавити ПШ на глибину до 200 мкм, то ми реалізуємо об'ємне джерело теплоти, змінюючи температуру у матеріалі за координатою z.

Розрахунок температур у ПШ проводимо на основі побудованої математичної моде- лі рухомого джерела теплоти гаусового типу (з врахуванням коефіцієнта зосередженості) для напівобмеженого тіла.

В основу покладено рівняння теплопровідності для напівобмеженого тіла 3 такими початковими та граничними умовами:

$$
\begin{gathered}
\frac{\partial \mathrm{T}}{\partial \mathrm{t}}=\mathrm{a}^{2}\left(\frac{\partial^{2} \mathrm{~T}}{\partial \mathrm{x}^{2}}+\frac{\partial^{2} \mathrm{~T}}{\partial \mathrm{y}^{2}}+\frac{\partial^{2} \mathrm{~T}}{\partial \mathrm{z}^{2}}\right) ; \\
-\infty<\mathrm{x}<+\infty ;-\infty<\mathrm{y}<+\infty ; 0 \leq \mathrm{z}<+\infty ; \mathrm{T}(\mathrm{x}, \mathrm{y}, \mathrm{z}, 0)=\mathrm{T}_{0} ; \\
\left.\lambda \frac{\partial \mathrm{T}}{\partial \mathrm{z}}\right|_{\mathrm{z}=0}=\mathrm{F}_{\mathrm{n}}\left(\mathrm{x}_{0}-\mathrm{V}_{\text {пот }} \cdot \mathrm{t}, \mathrm{y}, 0, \mathrm{t}\right)-\mathrm{L}_{\mathrm{n}}\left(\mathrm{x}, \mathrm{y}, 0, \mathrm{t}, \mathrm{T}_{\mathrm{z}=0}\right) ; \\
\left.\frac{\partial \mathrm{T}}{\partial \mathrm{x}}\right|_{\mathrm{x}=\mathrm{x}_{1}}=\left.\frac{\partial \mathrm{T}}{\partial \mathrm{x}}\right|_{\mathrm{x}=\mathrm{x}_{0}}=\left.\frac{\partial \mathrm{T}}{\partial \mathrm{y}}\right|_{\mathrm{y}=\mathrm{y}_{1}}=\left.\frac{\partial \mathrm{T}}{\partial \mathrm{y}}\right|_{\mathrm{y}=\mathrm{y}_{0}}=\left.\frac{\partial \mathrm{T}}{\partial \mathrm{z}}\right|_{\mathrm{z}=\mathrm{z}_{0}}=0,
\end{gathered}
$$

де $\mathrm{F}_{\mathrm{n}}\left(\mathrm{x}-\mathrm{V}_{\text {пот }} \cdot \mathrm{t}, \mathrm{y}, 0, \mathrm{t}\right)$ - функція розподілу інтенсивності електронного потоку на поверхні матеріалу за координатами $x, y, z$ та чаcoм t; $\mathrm{L}_{\mathrm{n}}\left(\mathrm{x}, \mathrm{y}, 0, \mathrm{t}, \mathrm{T}_{\mathrm{z}=0}\right)$ - розподіл потоку, обумовленого леткістю матеріалу з поверхні розплаву у вакуум за координатами $x, y, z$ та часом t; T(K) - температура в матеріалі; $\mathrm{T}_{0}$ температура попереднього нагріву матеріалу; a - коефіцієнт температуропровідності матеріалу; $\lambda$ - коефіцієнт теплопровідності матеріалу.

3 врахуванням явища леткості матеріалу скла використовуємо розв'язок рівняння [9]:

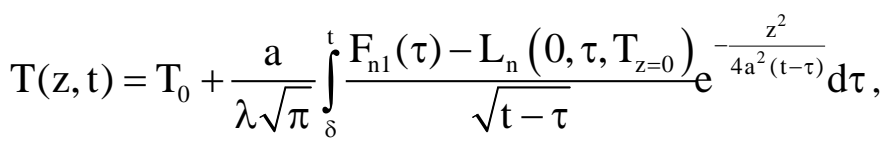

де $\mathrm{L}_{\mathrm{n}}\left(0, \tau, \mathrm{T}_{\mathrm{z}=0}\right)=15 \cdot \mathrm{L} \cdot 10^{\mathrm{p}_{1}-\frac{\mathrm{p}_{2}}{\mathrm{~T}_{\mathrm{z}=0}(\tau-\delta)}}-$ розподіл теплового потоку з поверхні матеріалу у вакуум, обумовлений леткістю розплаву. Рівень термічного впливу електронного потоку на матеріал (нагрів, проплавлення, випаровування) визначається, з одного боку, теплофізичними властивостями матеріалу, 3 іншого боку повною потужністю електронного потоку, його питомою потужністю та часом його дії на матеріал, рис. 1 , рис. 2.

На рис. 2 представлені залежності глибини проплавлення $\mathrm{h}_{\text {пр }}$ пластини електроннопроменевою стрічкою від питомої потужності стрічки $\mathrm{P}_{\text {пит }}$.

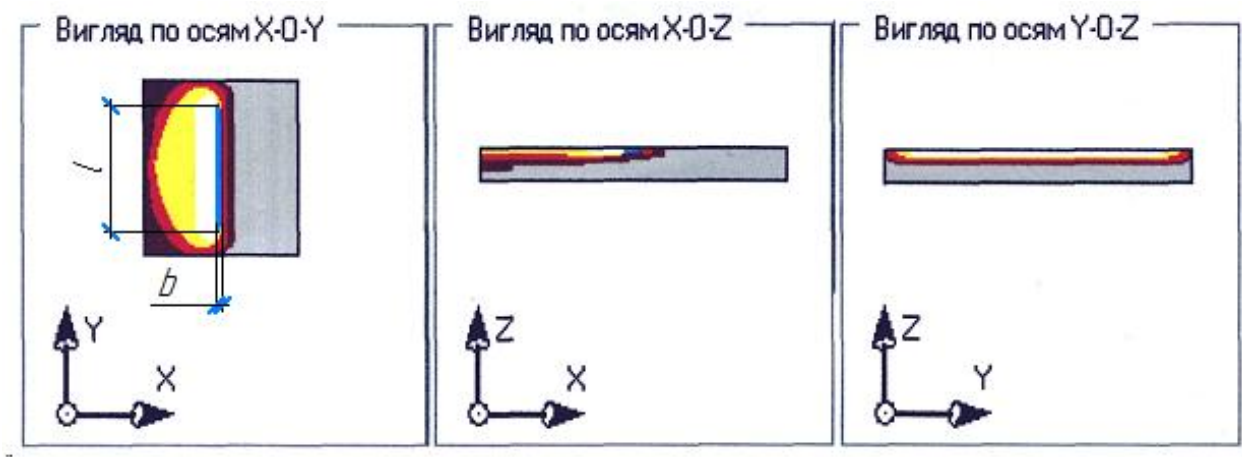

Рис. 1. Змодельований розподіл температурних полів в фотопластині за координатами $\mathbf{x , y}, \mathbf{z}$, в залежності від режимів обробки рухомим стрічковим електронним потоком: $P_{\text {пит }}=10 \cdot 10^{3} \mathrm{BT} / \mathrm{cm}^{2} ; V_{\text {пот }}=10 \mathrm{~cm} / \mathrm{c}$ 


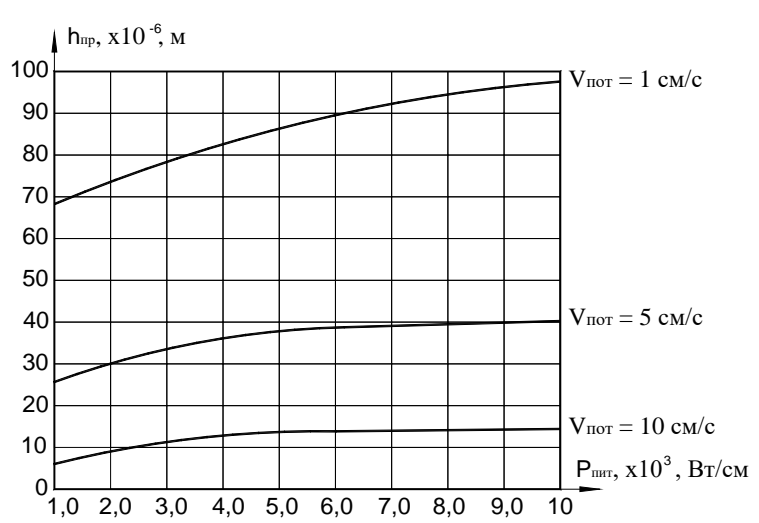

Рис. 2. Розрахункові залежності глибини про-

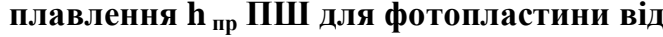
питомої потужності електронного потоку $P_{\text {пит }}$.

Характерною $є$ різниця у конденсації водяної пари на обробленій електронним потоком та необробленій поверхні скла. Таку відмінність можна спостерігати на поверхні фотопластини за плямами дихання після маскування цієї поверхні з'ємною металевою маскою (наприклад, смужка 3 фольги $\mathrm{Ni}$ ) та обробки електронним потоком, рис. 3.

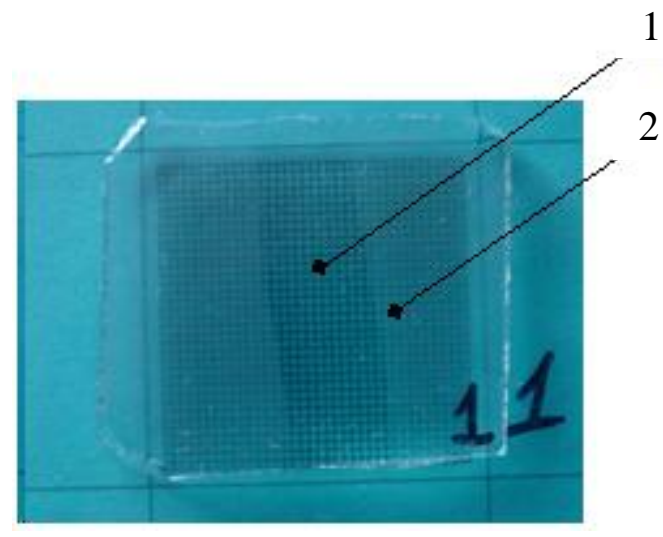

Рис. 3. Поверхня фотопластини, яка оброблена електронним потоком через маску та змочена парою води

Експериментально отримані результати 3 металізації поверхні фотопластин алюмінієм i електронно-променевої мікрообробки наведено в таблиці 1.

\section{Порівняльні характеристики поверхні фотопластини за методом [10]} та методом електронно-променевої мікрообробки

\begin{tabular}{|c|c|c|}
\hline $\begin{array}{c}\text { Підготовка поверхні пластини } \\
\text { до металізації }\end{array}$ & $\begin{array}{c}\text { Брак за зовнішнім } \\
\text { виглядом, \% }\end{array}$ & 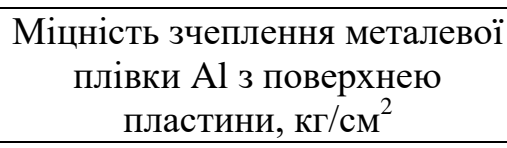 \\
\hline \multicolumn{3}{|c|}{ Травлення в розчині, г/л, за відомим способом [10] } \\
\hline Сульфат заліза 60, & 8 & 25,0 \\
\hline Сірчана кислота 75 & 6 & 26,5 \\
\hline Сульфат заліза 70, & 4 & 26,6 \\
\hline Сірчана кислота 80 & 4 & 26,8 \\
\hline Сульфат заліза 80, & 6 & 26,6 \\
\hline Сірчана кислота 90 & 6 & 26,6 \\
\hline \multicolumn{3}{|c|}{ Електронно-променева мікрообробка } \\
\hline $\begin{array}{c}\text { Питома потужність: } \mathrm{P}_{\text {пит }}=10^{1} \mathrm{BT} / \mathrm{cm}^{2}, \\
\text { Швидкість обробки: } \mathrm{V}=1 \mathrm{~cm} / \mathrm{c}\end{array}$ & 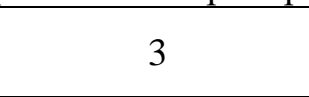 & 27,3 \\
\hline $\begin{array}{c}\text { Питома потужність: } \mathrm{P}_{\text {пит }}=2 \cdot 10^{1} \mathrm{BT} / \mathrm{cm}^{2} \text {, } \\
\text { Швидкість обробки: } \mathrm{V}=2,5 \mathrm{~cm} / \mathrm{c}\end{array}$ & 2 & 27,1 \\
\hline $\begin{array}{l}\text { Потужність потоку: } \mathrm{P}_{\text {пит }}=10^{2} \mathrm{BT} / \mathrm{cm}^{2}, \\
\text { Швидкість обробки: } \mathrm{V}=2,5 \mathrm{~cm} / \mathrm{c}\end{array}$ & 2 & 27,4 \\
\hline $\begin{array}{c}\text { Потужність потоку: } \mathrm{P}_{\text {пит }}=10^{2} \mathrm{BT} / \mathrm{cm}^{2}, \\
\text { Швидкість обробки: } \mathrm{V}=1,5 \mathrm{~cm} / \mathrm{c}\end{array}$ & 1 & 27,1 \\
\hline $\begin{array}{c}\text { Потужність потоку: } \mathrm{P}_{\text {пит }}=0,5 \cdot 10^{2} \mathrm{BT} / \mathrm{cm}^{2} \text {, } \\
\text { Швидкість обробки: } \mathrm{V}=5 \mathrm{~cm} / \mathrm{c}\end{array}$ & 1,5 & 27,2 \\
\hline
\end{tabular}

При такій обробці фотопластин: 1) питома потужність $\mathrm{P}_{\text {пит }}=10^{1}-0,5 \cdot 10^{2} \mathrm{BT} / \mathrm{cm}^{2} \mathrm{i}$ швидкістю $0,1 \ldots .5 \mathrm{~cm} / \mathrm{c}$ забезпечує вплив елек- тронного потоку лише на ПШ з речовинами, якими він заповнений; 2) хімічні елементи і сполуки, якими заповнений ПШ силікатного 
скла: $\mathrm{H}^{+}, \mathrm{H}_{2} \mathrm{O}, \mathrm{H}_{3} \mathrm{O}, \mathrm{H}_{3} \mathrm{O}^{+}, \mathrm{SiOH}, \mathrm{Na}, \mathrm{K}, \mathrm{Na}^{+}$, $\mathrm{K}^{+}, \mathrm{NaOH}, \mathrm{KOH}, \mathrm{Si}-\mathrm{O}$, (Si-O-Si)m тощо) дисоціюють на слабко зв'язані хімічні елементи та сполуки: $\mathrm{H}_{2}, \mathrm{~N}^{+}, \mathrm{O}_{2}, \mathrm{C}, \mathrm{CO}_{2}, \mathrm{~N}_{2}, \mathrm{H}_{2} \mathrm{O}$ та інші і десорбують у вакуум, а структура ПШ перебудовується.

\section{Висновки:}

1. Поверхня фотопластин i їх ПШ після електронно-променевої мікрообробки змінює свої властивості, що забезпечує покращення зчеплення металевої плівки $\mathrm{Al}$, нанесеної у вакуумі.

2. Низькоенергетичний електронний потік 3 енергією $\mathrm{E} \leq 8$ кеВ може використовуватися в якості інструменту для спрямованої зміни нанорельєфу поверхні та фізико-хімічного стану приповерхневого шару скла після будьякого його шліфування і полірування.

3. Зміна фізико-хімічного стану приповерхневого шару технічного силікатного скла 3 використанням електронно-променевого методу його мікрообробки може вигідно використовуватися в прецизійних технологіях мікрообробки технічного скла.

\section{Список літератури}

1. Буркат Т. М., Добычин Д. П., Пальтиель Л. Р. Кинетика и механизм сорбции воды на оптической поверхности кварцевого стекла. Докл. АН СССР. 1990. Т. 310. № 2. C. 376-379.

2. Пальтиель Л. Р. Структура и адсорбционные свойства поверхности кремнесодержащих оптических материалов и их модифицирующих покрытий: автореф. дис... канд. химич. наук: Ленинград, 1990. 19 с.

3. Глебов Л. Б., Ильин В. Г., Моисеев В. В. Научные основы ионнообменного синтеза элементов градиентной оптики. Стеклообразное состояние. Труды ХІІІ Всесоюзного совещания. Ленинград, 1986. С. 125-139.

4. Глебов Л. Б., Докучаев В. Г., Евстропьев Г. Т. Влияние структурных микронапряжений на формирование показателя преломления стекол при низкотемпературном ионном обмене. Физика и химия стекла. 1988. Т. 14. № 1. С.79-86.

5. Топорец А. С. Оптика шероховатой поверхности. Л.: Машиностроение, Ленинградское отделение, 1988. $191 \mathrm{c.}$

6. Богданов А. П., Бунин И. Г. Доводка формы оптической поверхности ионным пучком малого сечения, управляемым програ- мированным перемещением. ОМП. 1988, №2. C. 39-42.

7. Стогний А. И., Новицкий Н. Н., Стукалов О. М. Ионно-лучевое полирование наноразмерного рельефа поверхности оптических материалов. Письма в ЖТФ, Т. 28. Вып. 1. 2002. С. 39-47.

8. Анищенко Л. М., Лавренюк С. Ю. Математические основы проектирования высокотемпературных технологических процессов. М.: Наука, 1986. 80 с.

9. Щерба А. І., Канашевич Г. В., Дробот I. В., Алгоритм керування якістю поверхневого шару оптичних матеріалів при електроннопроменевій мікрообробці. Вісник Наи. техн. ун-ту "ХПI" : зб. наук. пр. Темат. вип.: Математичне моделювання в техніиі та технологіях. Харків : НТУ "ХПІ". 2012. № 27. C. 231-239.

10.А. с. 1488270 СССР, МКИ4 С 03 С15/00. Способ подготовки поверхности оптического стекла / А. П. Жужнева, В. П. Маслов, А. В. Тарадов, А. Н. Старшов, И. В. Калиниченко (СССР). № 4278563/23-33 заявл. 08.06 .87 ; опубл. 23.06.89, Бюл. № 23. 1 c.

\section{References}

1. Burkat T. M., Dobychin D P, Paltiel L.R. (1990) Kinetics and mechanism of water sorption on the optical surface of quartz glass // Rep. of the USSR Academy of Sciences. T. 310. No. 2. C. 376-379.

2. Paltiel L. R. Structure and adsorption properties of the surface of siliceous Dissertation diss. Cand. Chemistry: Leningrad. 1990. 19 p.

3. Glebov L. B., Ilyin V. G., Moiseev V. V. (1986) Scientific bases of ion-exchange synthesis of elements of gradient optics. Glassy state. Proceedings of the 13th All-Union Conference. Leningrad. P. 125-139.

4. Glebov L. B., Dokuchaev V. G., Evstropyev G. T. (1988) The influence of structural microstresses on the formation of the refractive index of glasses during low-temperature ion exchange. Physics and chemistry of glass. V. 14 № 1. P. 79-86.

5. Toporets A. S. (1988) Optics of a rough surface. L.: Mechanical Engineering. Leningrad Branch. $191 \mathrm{s.}$

6. Bogdanov A. P., Bunin I. G. (1988) Finishing of the shape of the optical surface by an ion beam of small cross section, controlled by programmed displacement. $O M P$. № 2. P. 39-42. 
7. Stogniy A. I., Novitsky N. N., Stukalov O. M. (2002) Ion-beam polishing of nanoscale topography of optical materials. Letters to ZhTF, t 28, issue 1. P. 39-47.

8. Anishchenko L. M., Lavrenyuk S. Yu. (1986) Mathematical foundations of designing hightemperature technological processes. M.: Nauka. 80 p.

9. Shcherba A. I., Kanashevich G. V., Drobot I. V., The algorithm for controlling the quality of the surface layer of optical materials under electron-beam microprocessing.
Herald of the National tech Univ "HPI": Coll. sciences Temat ave. vip : Mathematical modeling in technology and technology. Kharkiv: NTU "KhPI". 2012. No. 27. P. 231-239.

10.Author's certificate 1488270 USSR, MKI4 C 03 C15 / 00. Method for preparing the surface of optical glass/ A. P. Zhuzhneva, V. P. Maslov, A. V. Taradov, A. N. Starshov, I. V. Kalinichenko (USSR). - No. 4278563 / 23-33 Appl 08.06.87; Publish 23.06. 1989, Bull №. 23. 1 p.

M. V. Holub, assistant

S. M. Matsepa, assistant

H. V. Kanashevych, Dr.Tech.Sc., professor

O. S. Alekseeva, Ph.D., associate professor

I. V. Khyzhniak, Ph.D., senior lecturer

P. P. Dmitrenko, assistant

Cherkasy State Technological University

Shevchenko blvd, 460, Cherkasy, 18006, Ukraine

\section{METALIZATION OF A TECHNICAL GLASS WITH USING THE ELECTRON BEAM METHOD OF A SURFACE MICROPROCESSING}

The data from electron beam processing are presented for improving the adhesion strength of metal films. The basis of this is the directed change in the physicochemical properties of the nearsurface layer of the glass by processing a band electron beam with an electron energy of E $\leq 8 \mathrm{keV}$. The results can be used in precision micro-optics and integral optics technologies.

Keywords: electronic stream, electron beam processing, electron beam microprocessing, nearsurface layer of glass, silicate glass.

Стаття надійшла 04.06.2018.

Статтю представляє Г. В. Канамевич, д.т.н., професор. 